\title{
A New Case of Epsilon Wave on Loop Recorder
}

\section{Fontaine GH, Waintraub X, Li G and Gandjbahch E}

Hôpital de La Salpêtrière, Université Pierre et Marie Curie 75013 Paris

Corresponding author: Fontaine GH, Hôpital de La Salpêtrière, Université Pierre et Marie Curie 75013 Paris, France, Tel: 33142160000 ; EMail: guy.fontaine2@numericable.fr

Received: 23 May 2016; Accepted: 25 May 2016; Published: 27 May 2016

Citation: Fontaine GH, Waintraub X, Li G, et al. A New Case of Epsilon Wave on Loop Recorder. Arch Can Res. 2016, 4: 2.

\section{Image Case}

Epsilon wave in ARVD is the marker of slow conduction (parietal block) observed on the right precordial leads as opposed to the left precordials. It is the result of a slowdown of conduction in the epicardial layers of RV and LV apex due the presence of a trouble in development producing apoptosis and fat (Kim Nature 2013) instead of cardiomyocytes [1-3].
However, in the large majority of patients this phenomenon is too weak to produce significant waves on standard ECG recording [4].

Here, we present a new case in which the Epsilon wave is present on the surface ECG but is also observed on the implanted loop recorder giving a confirmation of the previous description (Europace in press) (Figure 1).
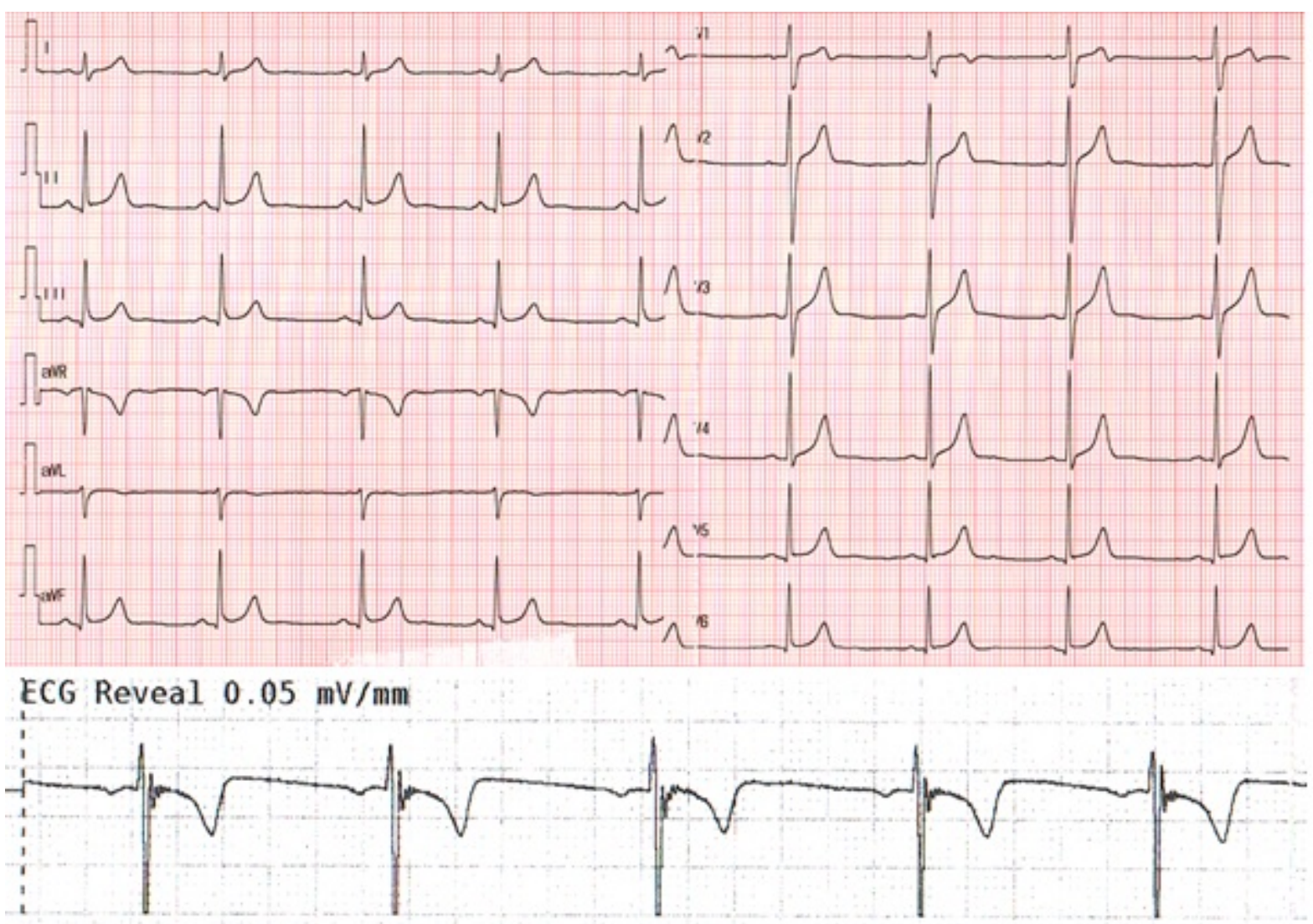

Figure 1 Epsilon waves obtained by the recorder is up to $200 \mathrm{~ms}$. On the ECG the Epsilon wave is visible on leads: III, aVF, V1. Also note the reduced amplitude and notch on the second QRS in V1 suggesting an unstable intramyocardial delay of conduction also visible on the third QRS complex of loop recorder.

Finally it is also confirmed that the loop which has an interelectrode distance of $6 \mathrm{~cm}$, is a very sensitive marker of ARVD which could be also obtain with bipolar chest leads called "the Fontaine lead system" [5].

\section{References}

1. Fontaine $G$, Guiraudon $G$, Frank R, Vedel J, Grosgogeat $Y$, et al. (1977) Stimulation Studies and Epicardial Mapping in Ventricular Tachycardia: Study of Mechanisms and Selection for Surgery. In- 
Reentrant Arrhythmias - Kulbertus H.E. Edn, MTP Lancaster. Reentrant Arrhythmias 334-350.

2. Fontaine G, Guiraudon G., Frank R (1978) Intramyocardial Conduction Defects in Patients Prone to Ventricular Tachycardia. Excerpta Medica Amsterdam 39-79.

3. Fontaine G, Frank R, Fontaliran F, Lascault G, Tonet J (1991) Right Ventricular Tachycardias. In- Cardiology Parmley WW, Chatterjee K Edn. Lippincott Philadelphia 1-18.
4. Zhang L, Liu L, Kowey PR, Fontaine GH (2014) The electrocardiographic manifestations of arrhythmogenic right ventricular dysplasia. Curr Cardiol Rev 10: 237-245.

5. Gottschalk B, Gysel M, Barbosa-Barros R, De Sousa Rocha RP, Pérez-Riera AR, et al. (2014) The use of fontaine leads in the diagnosis of arrhythmogenic right ventricular dysplasia. Ann Noninvasive Electrocardiol 19: 279-284. 